\title{
An overview of salient factors, relationships and values to support integrated energy-economic system dynamics modelling
}

\author{
Martin de Wit ${ }^{1 *}$, Matthew Heun², Douglas Crookes ${ }^{1}$ \\ 1. Faculty of Economics and Management Sciences, School of Public Leadership, Stellenbosch University, \\ Private Bag X1, Matieland, 7602 \\ 2. Engineering Department, Calvin College, 3201 Burton St. SE, Grand Rapids, MI, USA
}

\begin{abstract}
Integrated energy-economic modelling is needed to support the development of energy and climate policies. This study asserts that it is important to consider a system dynamics modelling approach that includes dynamics, endogenous treatment of uncertainty and risks, and both aggregate economic and disaggregate technical or engineering levels of analysis. The study examined the economic growth and the factors of production, elasticities, macroand technical substitutability; energy cost shares, heat engine efficiencies and energy services efficiencies. Emphasis was laid on the support of the future development of integrated energy-economic models covering (a) the key factors or components; (b) the relationships among these components; (c) a quantification of parameters; and (d) the implications for the development of an integrated energyeconomic system dynamics model. The study suggested the following: a non-linear relationship in production and consumption; large variations among price and income elasticity values across time frames, across countries and regions, and across energy goods; a far from perfect substitution among factors of production and among energy goods on a macro-level; technical/engineering limits
\end{abstract}

to substitution on a micro-level; and engineering and behavioural limits on what can be achieved with increased efficiencies. The study argues that integrated energy-economic modelling intensifies the accounting for the factors, relationships, quantifications, and implications, and that this practice allows for such models to describe a complex, emergent energy-economic reality that informs better energy policy.

Keywords: energy-economic modelling; elasticities; technical substitution; energy efficiency; energy cost share

\section{Highlights}

- Integrated energy-economic modelling needs to include physical and economic aspects.

- Such models need to build on empirically verifiable relationships among key factors.

- The main factors and interrelationships for energy-economic systems were developed.

- Key factors identified are production, elasticities, substitutability (macro- and technical), energy cost share, heat engine efficiency, and energy services efficiency.

Journal of Energy in Southern Africa 29(4): 27-36

DOI: http://dx.doi.org/10.17159/2413-3051/2018/v29i4a3417

Published by the Energy Research Centre, University of Cape Town ISSN: 2413-3051 http://journals.assaf.org.za/jesa

Sponsored by the Department of Science and Technology

\footnotetext{
* Corresponding author: Tel. (+27) 21808 4273;

email: mdewit@sun.ac.za
} 


\section{Introduction}

Academic and policy debates on how energy and carbon emission limits are influencing real economies worldwide are once again demanding serious attention. Tverberg (2012) pointed out an inevitable recessionary feedback effect and a reinforcement of financial crises from rising fossil fuel, notably oil, prices. Dolan (2001), on the other hand, highlighted the ability of the market mechanism, price incentives and the protection of property as superior mechanisms to circumvent fossil fuel depletion and rising prices.

It is becoming clear that, with rising public policy stakes on an increasingly complex and risky topic, partial analysis will not be sufficient. The International Monetary Fund emphasised the need for combining both geological and economic/technological analyses in one integrated model (Benes et al., 2012; Kumhof \& Muir, 2012). Kumhof and Muir (2012) indicated how oil supply shocks could lead to large variations in simulated outcomes if certain modelling assumptions, such as elasticities, substitutability, and production functions, were changed. The study recommended that future research focuses on 'a multidisciplinary approach to modelling, which better represents the dependence of production technologies on physical processes'.

Much research focused on the review and development of integrated energy-economy models (Bashmakov, 2007; Kümmel, et al., 2010; Stern, 2011a). Brandt (2010) reviewed 45 mathematical models of oil depletion in four categories: Hubbertmethod; other curve-fitting methods (exponential and Gaussian); simulation models of resource extraction and discovery; and economics (focused on investment and prices). None of these models bridged the energy-economy gap and Brandt (2010) concluded that they 'have fared poorly in predicting global oil production, [and] the greatest promise ... lies in simulation models that combine both physical and economic aspects of oil production'.

Clearly, research and modelling work are needed in the field of integrated economic-energy modelling and the present study's objective was to contribute to identifying the salient factors, relationships and values that could support integrated energyeconomic modelling with a focus on South Africa. Section 2 presents the systems methodology taken. Section 3 reviews the salient components and relationships in integrated energy-economic modelling. Section 4 gives a brief outline of the proposed modelling framework for South Africa, and conclusions are drawn in Section 5.

\section{Methodology}

It is imperative to have a system dynamics modelling approach that includes dynamics, endogenous treatment of uncertainty and risks, and both aggregate economic and disaggregate technical or engineering levels of analysis. This modelling approach is a well-established technique (Sterman, 2000) characterised by non-linearities and feedback between the components in the model and is well suited to modelling complex socio-economic phenomena (Crookes et al., 2013). Its application in the energy field is substantial, with the focus on energy inputs through biodiesel (Musango et al., 2012), coal (Nkambule \& Blignaut, 2017), invasive alien plants (Mudavanhu et al., 2016; Vundla et al., 2016; Nkambule et al., 2017) as well as labour inputs to the electricity sector (Ogano \& Pretorius, 2017).

The present study considered several factors that had not yet been included in integrated energy-economic system dynamics models. The nomenclature of systems thinking was followed in terms of function, components and the relationships among these components to indicate a framework by which future modelling efforts could be informed (Meadows, 2008). A dynamic process unfolds out of the interactions among system components, often with feedback loops reinforcing or counteracting original changes in the system (Deaton \& Winebrake, 2000). It is crucial that models are built on the basis of best available science on causeeffect relationships because complex system patterns can emerge over time from very simple interactions. This study organised surveys on energyeconomy interactions into subsections covering (a) the key factors or components; (b) the relationships among these components; (c) a quantification of parameters; and (d) implications for the development of an integrated energy-economic system dynamics model. A synopsis of the most important model features is presented with additional information available in the supplementary file. ${ }^{1}$

\section{Components and relationships in energy- economy interactions \\ 3.1 Economic growth and the factors of production}

Factors and components

In economic growth theory, changes in output $(Q)$ are explained by a set of input factors: capital $(k)$, labour $(l)$, land $(n)$, energy $(e)$, materials $(m)$, and knowledge $(h)$. The selection of input factors is guided by economic growth theory. There are two primary types of growth theories: exogenous and endogenous; a discussion of these is included in the supplementary file (Section 1). The advantage of the system dynamics modelling approach is that it provides a means of modelling all these different types of growth theories for neoclassical models (Crookes \& De Wit, 2014), Schumpeterian growth models (Castellacci, 2018), and the economic longwave (Sterman, 1985, 1986). However, although the use of these growth theories in system dynamics 
models is recognised in literature, it is not fully realised in energy-economic systems modelling.

\section{Relationships}

Not only the production factors differ in economic growth theory, but also the functional forms (equations) used in modelling (Ayres \& Warr, 2005; Mishra, 2007). The functional relationships between the input factors (and in certain cases the dis-utilities of environmental pollution and waste) and output have been of the form Constant elasticity of substitution (CES) (with special cases Linear, Cobb-Douglas, and Leontief), Translog, Quadratic, or Linear exponential (Linex). In most cases of mainstream neo-classical economic growth modelling, CES or the special form Cobb-Douglas are used. Functional forms are described in detail elsewhere (Ayres \& Warr, 2005; Mishra, 2007). Implicit in the selection of functional form is substitutability among inputs, a deeply contentious issue among economists. One's view of the role of thermodynamics in economic growth (Daly, 1997) informs assumptions about substitutability. The substitutability from both macro-economic and technical or engineering substitutability points of view are discussed in Sections 3.3 and 3.4.

\section{Quantification}

Quantification of economic growth models is accomplished by fitting unknown parameters in the functional relationships as discussed above (elasticities of substitution, for an example) to achieve the best possible agreement with historical economic data. Quantified values therefore depend largely upon the economic growth theory employed and the functional form of the growth equation (Heun et al., 2017). The fitting process itself, is fraught with fitted parameters subject to much uncertainty.

\section{Implications}

Earlier debates in economics concentrated on the theoretical validity of production functions, mainly focusing on how aggregate capital is measured (Robinson, 1953), a debate that has not been resolved yet (Cohen \& Harcourt, 2003). Shaikh (2005) further asserts that even if aggregate production functions 'appear to work on an empirical level, they provide no support for the neo-classical theory of aggregate production and distribution'. The important point for integrated system dynamics modelling approach is that the levels and rates of change in the factors of production and limitations on output in the economy are both dependent on the functional form selected. It would be wrong to assume that macro-level aggregates are rooted in micro-foundations - specific micro-level, engineering limitations need to be specified and included in the modelling effort. Section 3.4 elaborates.

\subsection{Elasticities}

Factors and components

Elasticity refers to the sensitivity of one economic variable to another variable expressed as the ratio of percentage rates of change. Important economic variables for calculating elasticities for energy goods are the demand for an energy good, the price of the energy good, the income of the consumers demanding the good, the price of complements to and substitutes for the energy good, the supply of the energy good, the output of an energy good. and the inputs used in the production of the energy good (Varian, 1992).

\section{Relationships.}

The relationships among these variables, namely price elasticity of demand, price elasticity of supply, income elasticity of demand, cross-price elasticity of demand, and output elasticity are congruent with standard economic theory; modelling equations (Equation 1-6) are included in the supplementary file (Section 2). Elasticities are expressed over the short run and the long run, where 'long' and 'short' do not refer to time scales. In the short run, the quantity of at least one input is fixed, while in the long run, quantities of all inputs may vary.

\section{Quantification}

Most of the studies dealing with energy elasticities date from the 1970s and 1980s and more work is needed in deriving elasticities for contemporary energy regimes. Output elasticities should not be reported without clarity on the production function chosen, for reasons discussed in Section 3.1. For an example, production functions that include physical work as a factor of production will have larger output elasticities for energy than those that denote primary energy inputs by cost shares (Lindenberger \& Kümmel, 2011). Each energy carrier can be analysed independently. The price elasticity of demand for crude oil, kerosene, and gasoline are the most inelastic compared to other forms of energy, while the income elasticity of demand signal luxury goods for natural gas and crude oil and necessity goods for gasoline, diesel, and petroleum. Price elasticity of supply is inelastic for all energy sources, with the notable exception of countries not part of the Organisation of Petroleum Exporting Countries in the short run (Ramcharran, 2002).

\section{Implications}

The choice of values for elasticities to be used in an integrated system dynamics model is not as straightforward as it may seem at first. When large variations among elasticity values occur across timeframes, across countries and regions, and across energy goods, an empirical approach is suggested specific to the research question at hand and the economic theory being employed. Ultimately, we 
desire a system dynamics model from which elasticities are a result rather than an input parameter. With such a model, the resulting elasticities can be compared to the above observations to validate that the model is correctly reproducing real-world economic behaviour.

\subsection{Macro-substitutability}

Factors and components

The elasticity of substitution measures how easily one input (in production) or good (in consumption) may be substituted for another. In an integrated energy-economy system dynamics model, the elasticity of substitution could indicate the substitution possible among the input factors of production $(k, l$, $e, m, h$ ) or among different energy types or energy carriers.

\section{Relationships}

Elasticity of substitution between two factor inputs or goods is measured as the percentage response of the relative marginal products of the two factors to the percentage change in the ratio of their quantities; Equation 7-8 are included in Section 3 of the supplementary file. The closer that the elasticity of substitution comes to unity, the higher the possibility of substitution between the two input factors. Conversely, the closer the elasticity of substitution comes to zero, the more complementary the input factors are to one another. The Cobb-Douglas production function assumes unitary factor substitution elasticity. Constant elasticities of substitution are assumed between factors of production when working with production functions specified as CES (Arrow et al., 1961). A very relevant variation of the elasticity of substitution is the elasticity of substitution between energy inputs that are environmentally benign and those that are not. Pelli (2011) estimated that clean and dirty inputs to the production of electricity in 21 countries are complementary. Another variation is interfuel substitutability. Stern and Kander (2012) published a meta-analysis on the topic and concluded that both the level of analysis and the type of fuel matter, and that substitution among energy sources is relatively easy at the industrial level; but that substitution of gas for electricity (and vice versa) or coal for electricity (and vice versa) at the industrial level are more difficult. Section 3.4 elaborates. Stern (2011b) also found that energy substitutability is practically more difficult to achieve at a macro-level. These findings imply that energy transitions at a macro-level is more difficult to achieve.

\section{Quantification}

Elasticities of substitution differ substantially among sectors and among type of inputs and goods (Koesler \& Schymura, 2012). Empirical work so far has demonstrated much lower than unitary substi- tution elasticities between capital and labour, capital and energy, and between combinations of capital/labour and energy as well as capital/energy and labour (Balistreri, et al., 2003; Okagawa \& Ban, 2008; Van der Werf, 2008; Koesler \& Schymura, 2012). Therefore, Koesler and Schymura contended that Cobb-Douglas and Leontief production functions, which assume unitary elasticity of substitution, must be rejected for most economic sectors.

\section{Implications}

Because the above reviews show elasticity of substitution below unity, none of the factor inputs are perfectly substitutable at the macro-level and all tend toward complementarity in varying degrees. Such results suggest that transitions from one production or consumption structure to another can be disruptive and that the transitions need to be modelled dynamically to the fullest extent possible. As Stern (2011b) pointed out, there are considerable differences among different definitions for substitutions and complementarity, and clarification is needed when stating modelling assumptions.

\subsection{Technical substitutability}

\section{Factors or components}

While the previous section covered macroeconomic substitutability among economic factors of production and among forms of energy, this section addresses technical substitutability from one type of energy to another, focusing on technical and physical constraints. There are capital and time horizon dependencies to primary and final energy substitutions; see Section 4 of the supplementary file for a list of factors. For an example, in the short run, electricity cannot be substituted for coal if the desired form of useful energy is heat and a coal-burning boiler is in place. In the long run, electricity could replace coal if electrical resistance heaters are purchased and installed. If mechanical drive on a factory assembly line is desired, electricity cannot be substituted for coal as a fuel for an in-place steam engine, but in the long-run, electricity could replace coal if an electric motor is emplaced. At the point of use, substitution among energy types (heat, mechanical work and light) is almost impossible. For an example, the human need for heat will not be satisfied by a spinning shaft (mechanical drive) or illumination (light). Neither heat nor light will move a vehicle whose wheels are connected to a driveshaft. And offices cannot be illuminated by a spinning shaft or a furnace.

\section{Relationships}

A complete world energy substitution to wind, water, and solar (WWS) primary energy sources and a fully-electric energy carrier system, is, with some exceptions, technically achievable today but 
requires massive infrastructure investments and comes with significant cost. From a technical point of view, key quantifiable measures and relationships for WWS energy substitutions include:

- capacity factors of WWS energy generating machines (ratio of actual energy production to energy production that would have occurred if the machine were operating continuously at rated capacity);

- various measures of electricity supply intermittency from WWS machines;

- marginal cost increases (or decreases) to consumers (and therefore the economy as a whole) for energy source and carrier substitutions, including both the incremental cost of WWS electricity and the cost for replacing obsoleted consumption machines (e.g. vehicles with internal combustion engines replaced by electric vehicles); and

- energy cost share in the economy (see Section 3.5).

\section{Quantification}

Although energy substitutions are technically possible, they must be bought at a price. Jacobson and Delucchi (2009) estimated the total cost for emplacing a WWS energy system to be USD 100 trillion over 20 years, or USD 5 trillion per year. The 2011 world's gross domestic product (GDP) at purchasing power parity (PPP) is estimated at USD 69 trillion per year (CIA, 2012), so the WWS plan would cost an additional approximately $7 \%$ of world's GDP for the following 20 years, just to emplace. Cost projections are difficult in the short-term and nearly impossible over a 20-40-year timeframe, but the WWS cost figure, in particular, is likely to be an underestimate for reasons outlined in Section 4 of the supplementary file. Both Moriarty (2011) and Tverberg (2009) placed the cost estimate at about USD 200 trillion or more over 20 years, or at least $14 \%$ of world's GDP over 20 years for emplacing the WWS system.

\section{Implications}

Understanding the technical aspects of energy substitutions leads to a conclusion that a worldwide transition away from fossil fuels and other nonrenewable energy sources toward renewable energy sources will be costly in terms of both money and time. Integrated energy-economy system dynamics models must account for both the cost to the economy of such a transition and the time to execute the transition. Additionally, marginal price changes that will accompany energy transitions should be included in such a model.

\subsection{Energy cost share}

Factors or components

Recently, the impact on economic growth of an economy's energy cost share has received attention in the literature. The components of energy cost share in a given time are energy type, energy price for each type, energy consumption rate for each type, and GDP. Equation 9 in Section 5 of the supplementary file calculates the energy cost share for an economy.

\section{Relationships}

Bashmakov (2007) showed that developed economies can sustain high total energy cost share above a threshold for a short period, of possibly two to three years, before recessionary pressures depress energy demand, stimulate energy efficien$\mathrm{cy}$, reduce energy prices, and return total energy cost share to its long-term sustainable range. On the other hand, reduction of total energy cost share below a lower bound provides economic stimulus, increases energy demand, provides upward pressure on energy prices and returns the energy cost share to its long-term sustainable range. Bashmakov (2007) speculated that 'energy affordability thresholds and behavioural constants' are responsible for the stable range of energy cost share over many decades. Embarking on a modern growth path appears to reduce the energy cost share in an economy from very high values, (indicating that nearly all economic activity is focused on procuring energy) to small values that remain within a stable range (Stern \& Kander, 2012).

\section{Quantification}

According to Bashmakov (2007), the stable range for economy-wide energy cost share is $8-10 \%$ for the United States and 9-11\% for the Organisation for Economic Co-operation and Development. The stable and narrow range of energy cost share for final consumers in the United States is $4-5 \%$ and in the OECD is 4.5-5.5\% (Bashmakov, 2007). The oil cost share threshold that correlates with United States recessions is approximately 5.5\% (Murphy \& Hall, 2011). Sweden's energy cost share has stabilised at $12 \%$ since 1970 , although it was nearly $100 \%$ in 1800 (Stern \& Kander, 2012). King et al. (2015) showed that the United Kingdom's cost share is now in the single digit percentages, but it was around $30 \%$ in the pre-industrial-revolution years between 1300 and 1600 . The South African case study is illuminating, for it shows the effects of energy cost share threshold as well as regional effects are important. South Africa has a very high dependence on oil imports: $95 \%$ of crude oil and $70 \%$ of liquid oil requirements are imported (Wakeford, 2012). Wakeford showed that a 1979 oil cost share spike to just below $5 \%$ did not correlate with a recession, because a simultaneous gold price spike offset the negative effect of the oil price spike. However, a 1985 South African oil cost share spike to 5\% correlated with a recession. The 1990 
Gulf War oil price spike was mitigated in South Africa by domestic coal-to-liquids (CTL) production capabilities. Since the end of apartheid in 1994, global oil price spikes have led to increased energy cost share in South Africa's economy because, firstly, the country is now integrated with the world economy and, secondly, the share of CTL in total consumed petroleum is declining because of increasing reliance on imported oil. Thus, the country's economy today may be more vulnerable to global oil price spikes than in the past. An oil cost share spike to nearly $7 \%$ preceded the 2009 recession. The present study shows that it is not energy price, per se, that impacts the economy. Rather, the energy cost share (and, perhaps more narrowly, oil cost share) is a likely key factor. The Swedish and United Kingdom examples show that energy cost shares evolve over time along a development path. The South African case study shows that regional and local considerations can be significant. It can be expected that a successful dynamic energy-economy model will exhibit a stable range for energy cost share of around $10 \%$ or less.

\section{Implications}

The dynamics of energy cost share should be a result of an integrated energy-economy system dynamics model rather than an input to that model. Thus, a successful integrated energy-economy system dynamics model should exhibit an energy cost share range above which recessionary pressures may limit economic growth or induce further innovation and below which economic growth is stimulated.

\subsection{Power plant efficiency}

\section{Factors or components}

Electric power plants are important generators of electricity, the most flexible energy carrier. Power plant operators pay for high temperature heat (typically in the form of coal or natural gas) and receive revenue from work. Many factors affect the profitability of power plants, including revenue rate, fuel price, operations and maintenance costs, and capital loan repayment costs. An integrated energy-economic understanding of power plants provides insight into the treatment of power plants in integrated energy-economy models.

\section{Relationships}

From a thermodynamic point of view, power plants are heat engines that take in high-temperature heat at a given rate and reject low-temperature heat at a different rate as they produce a rate of final energy, namely work in the form of electricity. Equation 10 13 for the thermal efficiency of a power plant's heat engine and its maximum efficiency are included in Section 6 of the supplementary file.

\section{Quantification}

The difference in efficiency for power plants operating at maximum power and maximum efficiency for the same high and low temperature is significant: a hypothetical coal-fired power plant operating with a high temperature of $565{ }^{\circ} \mathrm{C}$ and a low temperature of $25{ }^{\circ} \mathrm{C}$ would have a Carnot efficiency of 0.64 and efficiency at maximum power output of only 0.40 . There is, therefore, an economic incentive to operate heat engines with an efficiency that is significantly lower than the thermodynamic limit (in this case $38 \%$ lower).

\section{Implications}

Looking ahead, options for increasing the efficiency of power plants are constrained. Increasing a plant's high temperature, reducing its low temperature, or both, will improve the efficiency of heat engines operating at their maximum power point. Awkwardly, the lower bound on a plant's low temperature is given by the nearby water or ambient air temperature, thus offering no realistic possibility for efficiency improvement. Increasing a plant's maximum temperature is feasible only by employing higher-temperature (and, presumably, higher-cost) materials within power plant boilers, requiring technological breakthroughs in material science. Through many decades of similar power plant economics, no such important breakthroughs have been forthcoming. The present study suggests that any energy-economy system dynamics model assumes a fixed value of power plant efficiency that is roughly equivalent to today's value.

\subsection{Energy services efficiency}

Factors or components

The efficiency of converting raw energy carriers or intermediate energy products into energy services (such as light, motion, lifting, cutting and bending) is another important consideration for developing a dynamic energy-economy model. Improvements in energy services efficiency can have unexpected effects. Jevons (1866) was the first to suggest what has become known as the rebound effect, wherein an energy services efficiency intervention results in less energy savings than expected. Both direct, (usually behavioural) and indirect (usually economic) feedbacks can contribute to the rebound effect. An example of a direct (behavioural) feedback is that a light emitting diode bulb may be left 'on' longer when it is known that it consumes energy at a lower rate. An example of indirect (economic) feedback occurs when improved energy services efficiency reduces energy costs, thereby increasing cash in hand that is spent on other products and services that require energy to produce, distribute, and consume. Equations 14-16 for energy intensity and the rebound effect are included in Section 7 of the supplementary file. 


\section{Relationships}

Typically, increasing energy services efficiency is thought to decrease both energy consumption and energy intensity. However, an energy services efficiency intervention coupled with a strong rebound effect can increase total energy consumption of an economy, a phenomenon known as backfire. Jevons (1866) contended that increasing steam engine efficiency in early-industrial England led to an increasing rather than decreasing rate of coal use for the economy as a whole: Jevons' Paradox. For Warr et al. (2010:1914), the rebound effect (with backfire!) is what drives economic growth as it is known. This study's assertion was that:

energy efficiency improvements drive economic growth through [an effect similar to the] rebound effect. Ceteris paribus efficiency improvements provide more useful work per unit of energy purchased and hence drive down the costs of products and services. Lower prices stimulate demand enabling economies of scale and $\mathrm{R} \& \mathrm{D}$. The resultant product, process, and price improvements increase revenues and further stimulate growth.

\section{Quantification}

Economists are divided on both the existence and magnitude of the rebound effect at both the microand macro-levels. Sorrell (2009) admitted that the rebound effect is difficult to test empirically because of the many interacting factors at play in the feedback loops. It was noted that the evidence for Jevons' Paradox (backfire) is inconclusive at this time, and that perceptions of the magnitude of the rebound effect are coloured by assumptions about the role of energy in economic growth. Economists who contend that energy's role in economic growth is commensurate with its small cost share have typically found little evidence of the rebound effect (Berkhout et al., 2000; Schipper \& Grubb, 2000). In contrast, economists who believe that energy's role in economic growth far exceeds its cost share have tended to find that rebound effects are significant (Sorrell, 2007; Sorrell, 2009).

\section{Implications}

The present study recommends that a rebound effect be included in energy-economy system dynamics models as an adjustable exogenous parameter that can be used for sensitivity studies. Further, it is postulated that energy intensity should be an outcome of (not an input to) an energy-economy system dynamics model. A successful integrated energy-economy system dynamics model will predict energy intensity that is in line with today's values.

\section{Some implications for the South African context}

An analysis of energy efficiencies, costs and factors is important in the southern African context. For example, $66 \%$ of households in southern Africa depend on cheap fuel sources such as fuelwood (Makonese et al., 2018). Although electrification has increased, most households cannot afford the appliances or the monthly electricity costs and continue to use cheaper fuels (Davis, 1998; Howells et al., 2005). Madubansi and Shackelton (2006) found that electricity accounted for $60 \%$ of expenditure on fuel sources in rural communities in South Africa, thus making those people highly vulnerable to price shocks. At the same time, $25 \%$ of households in southern Africa do not have access to electricity (Makonese et al., 2018). Bazilian et al. (2012) estimated that a tenfold increase in power generation would be required in sub-Saharan Africa for full access to be achieved by 2030 .

There has been much discussion around the need to transition to green energy uses (Swilling \& Annecke, 2012; Baker, et al., 2014), and the use of system dynamics models of energy use in South Africa to reflect this reality (Musango, et al., 2014). However, as Heun and De Wit (2012) contended, such transitions cannot be expected to be smooth. The present study points out that the situation in South Africa is exacerbated by decisions around energy mixes that are based on cost factors rather than efficiency and environmental considerations. South Africa historically had access to cheap but dirty fuel sources and the recent constructions of Kusile and Medupi power stations highlight the fact that South Africa is still heavily reliant on coal, albeit premised on clean coal technology.

The proposed system dynamics modelling framework in the present study provides a means of incorporating these factors into an energy-economic model for South Africa. For an example, elasticities may be estimated from system dynamics models to provide a better understanding of the effect of the fuel mix on demand. In other cases, functional relationships presented in the present study from the energy-economic literature may be incorporated into energy-economic system dynamics models to better understand factors driving demand and energy transitions. This is important in South Africa given the vulnerabilities of the economy to oil price shocks. Ultimately, system dynamics modelling is a tool to support decision-making and the review in the present study provides suggestions on how some of the challenges faced in the South African economy may be modelled in such a framework.

\section{Conclusions}

In response to both policy literature and academic literature calling for greater integration and multidisciplinary modelling approaches, this study pro- 
vided an overview of the main factors and interrelationships for energy-economic systems. The study found:

- non-linear relationships in production and consumption;

- large variations among price and income elasticity values across timeframes, across countries and regions, and across energy goods;

- far from perfect substitution among factors of production and among energy goods on a macro-level;

- engineering limits to fuel substitution on a micro-level; and

- engineering limits on efficiency and behavioural limits on what can be achieved with increased efficiencies.

The study considered the research call to continue to develop integrated energy-economic models. Yet, non-linearity, large variations and the existence of engineering and behavioural limits in the energyeconomy space all indicated a need for a specific focus on the nature of transitions as informed by a modelling approach that is able to capture complex dynamics, feedback loops and an endogenous modelling of risk. Integrated energy-economic modellers are encouraged to deepen their work to account for the factors, relationships, quantifications and implications outlined in this study. As complex system patterns can emerge over time from very simple interactions, there is a strong belief that such a modelling approach will assist in (i) accurately describing a complex, emergent energyeconomic reality, and in (ii) supporting better informed energy policy.

\section{Note}

1. Supplementary material can be found at https://journals.assaf.org.za/jesa/article/view/3417.

\section{References}

Arrow, K.J., Chenery, H.B., Minhas, B.S. and Solow, R.M. 1961. Capital-labour substitution and economic efficiency. The Review of Economics and Statistics 43 (3): 225-250.

https://doi.org/10.2307/1927286.

Ayres, R. and Warr, B. 2005. Accounting for growth: the role of physical work. Structural Change and Economic Dynamics 16 (2): 181-209. https://doi.org/10.1016/j.strueco.2003.10.003.

Baker, L., Newell, P. and Phillips, J. 2014. The political economy of energy transitions: the case of South Africa. New Political Economy 19 (6): 791-818. https://doi.org/10.1080/13563467.2013.849674.

Balistreri, E.J., Mcdaniel, C.A. and Wong, E.V. 2003. An estimation of US industry-level capital-labor substitution elasticities: Support for Cobb-Douglas. The North American Journal of Economics and Finance 14: 343-356.
https://doi.org/10.1016/S1062-9408(03)00024-X.

Bashmakov, I. 2007. Three laws of energy transitions. Energy Policy 35 (7): 3583-3594, https://doi.org/10.1016/j.enpol.2006.12.023.

Bazilian, M., Nussbaumer, P., Rogner, H.H., BrewHammond, A., Foster, V., Pachauri, S., Williams, E., Howells, M., Niyongabo, P., Musaba, L. and Gallachóir, B.Ó. 2012. Energy access scenarios to 2030 for the power sector in sub-Saharan Africa. Utilities Policy 20 (1): 1-16, https://doi.org/10.1016/j.jup.2011.11.002.

Benes, J., Chauvet, M., Kamenik, O., Kumhof, M., Laxton, D., Mursula, S. and Selodl, J. 2012. The future of oil: Geology versus technology. IMF Working Papers I12/109: 1-33.

Berkhout, P.H.G., Muskens, J.C. and Velthuijsen, J.W. 2000. Defining the rebound effect. Energy Policy 28 (6-7): 425-432. https://doi.org/10.1016/S0301-4215(00)00022-7.

Brandt, A.R. 2010. Review of mathematical models of future oil supply: Historical overview and synthesizing critique. Energy 35: 3958-3974. https://doi.org/10.1016/j.energy.2010.04.045.

Castellacci, F. 2018. Co-evolutionary growth: A system dynamics model. Economic Modelling 70: 272-287, https://doi.org/10.1016/j.econmod.2017.11.010.

CIA. 2012. The World Fact Book. Available at: https:/www.cia.gov/library/publications/the-worldfactbook/geos/xx.html (accessed on 20 December 2012).

Cohen, A.J. and Harcourt, G.C. 2003. Retrospectives: whatever happened to the Cambridge capital theory controversies? The Journal of Economic Perspectives 17 (1): 199-214. https://doi.org/10.1257/089533003321165010.

Crookes, D.J. and De Wit, M.P. 2014. Is system dynamics modelling of relevance to neoclassical economists? South African Journal of Economics 82 (2): 181-192. https://doi.org/10.1111/saje.12038.

Crookes, D.J., Blignaut, J.N., De Wit, M.P., Esler, K.J., Le Maitre, D.C., Milton, S.J., Mitchell, S.A., Cloete, J., De Abreu, P., Fourie (nee Vlok), H., Gull, K., Marx, D., Mugido, W., Ndhlovu, T., Nowell, M., Pauw, M. and Rebelo, A. 2013. System dynamic modelling to assess economic viability and risk trade-offs for ecological restoration in South Africa. Journal of Environmental Management 120: 138147, https://doi.org/10.1016/j.jenvman.2013.02.001.

Daly, H.E. 1997. Georgescu-Roegen versus Solow/Stiglitz. Ecological Economics 22 (3): 261266. https://doi.org/10.1016/S0921-8009(97)00080-3.

Davis, M. 1998. Rural household energy consumption: The effects of access to electricity-evidence from South Africa. Energy Policy 26: 207-217. https://doi.org/10.1016/S0301-4215(97)00100-6.

Deaton, M.L. and Winebrake, J.I. 2000. Dynamic modeling of environmental systems. New York: Springer. https://doi.org/10.1007/978-1-4612-1300-0.

Dolan, E.G. 2001. TANSTAAFL. A Libertarian Perspective on Environmental Policy. London: 
Searching Finance.

Heun, M.K., Santos, J., Brockway, P.E., Pruim, R.J., Domingos, T. and M. Sakai. 2017. From theory to econometrics to energy policy: Cautionary tales for policymaking using aggregate production functions. Energies 10 (203): 1-44.

https://doi.org/10.3390/en10020203.

Heun, M.K. and De Wit, M. 2012. Energy return on (energy) invested (EROI), oil prices, and energy transitions. Energy Policy 40: 147-158. https://doi.org/10.1016/j.enpol.2011.09.008.

Howells, M.I., Alfstad, T., Victor, D.G., Goldstein, G. and Remme, U. 2005. A model of household energy services in a low-income rural African village. Energy Policy 33: 1833-1851. https://doi.org/10.1016/j.enpol.2004.02.019.

Jacobson, M.Z. and Delucchi, M.A. 2009. A path to sustainable energy. Scientific American 301 (5): 38-45.

Jevons, W.S. 1866. The coal question, 2nd edition. London: Macmillan. Available at: http://oll.libertyfund.org/title/317.

King, C.W., Maxwell, J.P. and Donovan, A. 2015. Comparing world economic and net energy metrics, part 3: Macroeconomic historical and future perspectives. Energies 8 (11): 12997-13020. https://doi.org/10.3390/en81112347.

Koesler, S. and Schymura, M. 2012. Substitution elasticities in a CES production framework: An empirical analysis on the basis of non-linear least squares estimations. Available at: http://www.wiod.org/conferences/groningen/Paper_Koesler_Schymura.pdf. (accessed on 17 December 2012).

Kumhof, M. and Muir, D. 2012. Oil and the world economy: Some possible futures. IMF Working Paper 12/256: 1-31. https://doi.org/10.5089/9781475586640.001.

Kümmel, R., Ayres, R. and Lindenberger, D. 2010. Thermodynamic laws, economic methods and the productive power of energy. Journal of NonEquilibrium Thermodynamics 35 (2): 1-26. https://doi.org/10.1515/jnetdy.2010.009.

Lindenberger, D. and Kümmel, R. 2011. Energy and the state of nations. Energy 36 (10): 6010-6018. https://doi.org/10.1016/j.energy.2011.08.014.

Madubansi, M. and Shackleton, C.M. 2006. Changing energy profiles and consumption patterns following electrification in five rural villages, South Africa. Energy Policy 34 (18): 4081-4092. https://doi.org/10.1016/j.enpol.2005.10.011.

Makonese, T., Ifegbesan, A.P. and Rampedi, I.T. 2018. Household cooking fuel use patterns and determinants across southern Africa: Evidence from the demographic and health survey data. Energy \& Environment 29 (1): 29-48. https://doi.org/10.1177/0958305X17739475.

Meadows, D.H. 2008. Thinking in systems. A primer. Vermont: Chelsea Green Publishing.

Mishra, S.K. 2007. A brief history of production functions. MPRA Paper No. 5254. Available at: http://mpra.ub.uni-muenchen.de/5254/ (accessed on 17 December 2012).
Moriarty, T. 2011. Scientific American's 'A path to sustainable energy by 2030: the cost'. Available at: http://climatesanity.wordpress.com/2009/11/13/scientific-americans-a-path-to-sustainable-energy-by2030-the-cost-2/ (accessed on 11 November 2012).

Mudavanhu, S., Blignaut, J.N., Nkambule, N., Morokong, T. and Vundla, T. 2016. A cost-benefit analysis of using Rooikrans as biomass feedstock for electricity generation: A case study of the De Hoop nature reserve, South Africa. South African Journal of Economic and Management Sciences 19 (5): 788-813. http://dx.doi.org/10.17159/2222-3436/2016/v19n5a7.

Murphy, D.J. and Hall, C.A.S. 2011. Energy return on investment, peak oil, and the end of economic growth. Annals of the New York Academy of Sciences 1219 (1): 52-72. https://doi.org/10.1111/j.1749-6632.2010.05940.x.

Musango, J.K., Brent, A.C., Amigun, B., Pretorius, L. and Müller, H. 2012. A system dynamics approach to technology sustainability assessment: The case of biodiesel developments in South Africa.

Technovation 32 (11):639-651, https://doi.org/10.1016/j.technovation.2012.06.003. https://doi.org/10.1016/j.technovation.2012.06.003.

Musango, J.K., Brent, A.C. and Tshangela, M. 2014. Green economy transitioning of the South African power sector: A system dynamics analysis approach. Development Southern Africa 31 (5): 744-758. https://doi.org/10.1080/0376835X.2014.930792.

Nkambule, N.P. and Blignaut, J.N. 2017. The external costs of coal mining: The case of collieries supplying Kusile power station. Journal of Energy in Southern Africa 23 (4): 85-93. http://dx.doi.org/10.17159/sajs.2017/20160314.

Nkambule, N.P., Blignaut, J.N., Vundla, T., Morokong, T. and Mudavanhu, S. 2017. The benefits and costs of clearing invasive alien plants in northern Zululand, South Africa. Ecosystem Services 27: 203-223. http://dx.doi.org/10.1016/j.ecoser.2017.04.011.

Ogano, N.O. and Pretorius, L. 2017. Analysis of policy options for projects in the electricity sector in subSaharan Africa: a system dynamics approach. South African Journal of Industrial Engineering 28 (1): 20 35. https://dx.doi.org/10.7166/28-1-1607.

Okagawa, A. and Ban, K. 2008. Estimation of substitution elasticities for CGE models. Discussion Papers in Economics and Business 16 (2008).

Pelli, M. 2011. The elasticity of substitution between clean and dirty inputs in the production of electricity. Available at: http://works.bepress.com/mpelli/3/.

Ramcharran, H. 2002. Oil production responses to price changes: An empirical application of the competitive model to OPEC and non-OPEC countries. Energy Economics 24 (2): 97-106. https://doi.org/10.1016/S0140-9883(01)00091-3.

Robinson, J. 1953. The production function and the theory of capital. The Review of Economic Studies 21 (2): 81-106. https://doi.org/10.2307/2296002. 
Schipper, L. and Grubb, M. 2000. On the rebound? Feedback between energy intensities and energy uses in IEA Countries. Energy Policy 28 (6-7): 367388. https://doi.org/10.1016/S0301-4215(00)00018-5.

Shaikh, A. 2005. Nonlinear dynamics and pseudo-production functions. Eastern Economic Journal 31 (3): 447-466.

Sorrell, S. 2007. The rebound effect: An assessment of the evidence for economy-wide energy savings from improved energy efficiency. Sussex: UK Energy Research Centre, Sussex Energy Group, University of Sussex.

Sorrell, S. 2009. Jevons' paradox revisited: the evidence for backfire from improved energy efficiency. Energy Policy 37 (4): 1456-1469. https://doi.org/10.1016/j.enpol.2008.12.003.

Sterman, J.D. 1985. A behavioral model of the economic long wave. Journal of Economic Behavior \& Organization 6 (1): 17-53. https://doi.org/10.1016/0167-2681(85)90023-X.

Sterman, J.D. 1986. The economic long wave: Theory and evidence. System Dynamics Review 2 (2): 87 125. https://doi.org/10.1002/sdr.4260020202.

Sterman, J.D. 2000. Business dynamics: Systems thinking and modeling for a complex world. Boston, Massachusetts: Irwin McGraw-Hill.

Stern, D.I. 2011a. The role of energy in economic growth. Annals of the New York Academy of Sciences 1219 (1): 26-51. https://doi.org/10.1111/j.1749-6632.2010.05921.x.

Stern, D.I. 2011b. Elasticities of substitution and complementarity. Journal of Productivity Analysis 36 (1): 79-89. https://doi.org/10.1007/s11123-010-0203-1.

Stern, D.I. and Kander, A. 2012. The role of energy in the industrial revolution and modern economic growth. The Energy Journal 33 (3): 125-152. https://doi.org/10.5547/01956574.33.3.5.

Swilling, M. and Annecke, E. 2012. Just Transitions: Explorations of Sustainability in an Unfair World. Cape Town: UCT Press.

Tverberg, G.E. 2012. Oil supply limits and the continuing financial crisis. Energy 37: 27-34. https://doi.org/10.1016/j.energy.2011.05.049.

Tverberg, G.E. 2009. Scientific American's path to sustainability: Let's think about the details. The Oil Drum, 9 November. Available at: http://www.theoildrum.com/node/5939.

Van der Werf, E. 2008. Production functions for climate policy modeling: An empirical analysis. Energy Economics 30: 2964-2979. https://doi.org/10.1016/j.eneco.2008.05.008

Varian, H. 1992. Microeconomic analysis, 3rd edition. London: Norton.

Vundla, T., Blignaut, J.N., Nkambule, N., Morokong, T. and Mudavanhu, S. 2016. The opportunity cost of not utilising the woody invasive alien plant species in the Kouga, Krom and Baviaans catchments in South Africa. South African Journal of Economic and Management Sciences 19 (5): 814-830. https://doi.org/10.4102/sajems.v19i5.1603.

Wakeford, J. 2012. Socioeconomic implications of global oil depletion for South Africa: Vulnerabilities, impacts, and transition to sustainability. Ph.D. dissertation thesis, University of Stellenbosch, Stellenbosch, South Africa.

Warr, B.S., Ayres, R.U., Eisenmenger, N., Krausmann, F. and Schandl, H. 2010. Energy use and economic development: A comparative analysis of useful work supply in Austria, Japan, the United Kingdom and the US during 100 years of economic growth Ecological Economics 69 (10): 1904-1917. https://doi.org/10.1016/j.ecolecon.2010.03.021. 